\title{
The Textual Organization of Research Article Abstracts in an Indonesian Reputable Journal
}

\author{
Ardi Marwan \\ Department of Electrical Engineering and Language Center \\ State Polytechnic of Pontianak \\ Jalan Jend. Ahmad Yani, Pontianak, \\ Kalimantan Barat, Indonesia \\ Corresponding author: ardirini@yahoo.com
}

\begin{abstract}
This study reports on a research investigating the textual organization of research article abstracts published in a Scopus-indexed journal (i.e. Indonesian Journal of Applied Linguistics). Twenty-five RAs from three diferent publication years (2016, 2017 and 2018) were randomly selected. Santo's (1996) RAs analysis framework or known as five moves pattern cosisting of (i) situating the research, (ii) presenting the research, (iii) describing the methodology, (iv)summarizing the results, and (v) discussing the research were used to analyse the RAs. Firstly, the RAs were overviewed to examine the types of move structure used and secondly, further analysis was carried out to examine the specific features of each of the RAs. Results of this study revealed that nearly half of the RAs (10) were written with the S-P-M-R-D style whilst others were formatted according to the styles of P-M-R-D (5), P-M-R (5), S-P-M-R (3), P-S-M-D (1), and P-M-S-R-D (1). This study also yielded various outcomes regarding the specific features contained in the RAs suggesting that different ways in outlining moves is a possibility for this particular journal.
\end{abstract}

Keywords: Abstract; Move, Pattern, Structure

\section{Introduction}

Abstract is "one of the most central elements of an article, luring other people to read it and may also influence the acceptance of the article" (Belt, Mottonen, \& Harkonen, 2011, p.12). Although an abstract contains only a limited number of words (usually no more than 300 words), an author, particularly a novice one, may spend hours to write the good abstract. A poorly written abstract may cause an article be rejected for publication in a scholarly journal (Andrade, 2011). Thus, an author needs to develop a skill of how to write a good abstract. As Morton (2007) points out "writing an abstract is a skill in itself, and it is worth taking the effort to write one clearly"(p.36).

Generally, a research abstract, as Zanina (2017) argues, is used by readers for two reasons. Firstly, readers may read an abstract in order to grasp general information about a research study (e.g. aims, methods, findings, and conclusion). If they consider this study meets their interest and expectation, they may decide to continue reading the entire article. Secondly, abstract can also be used by readers to recall their memory about the basic content of a research article which they have read previously. Doing this helps them save much of their time but still allows them to gain important information about a research study (Pho, 2008). 
Some recently undertaken previous studies of research article abstracts have primarily focused on the identification of the rhetorical move structure of the abstracts. The newest one, Noorizadeh-Honami and Chalak (2018) investigated the types of move structure used in English and Persian RAs published English journals and Iranian journals respectively. In their study, it was revealed that most authors, regardless of their country of origin, adopted the IMRD (introduction, method, results and discussion) and IMR model in their RAs. Zanina (2017) carried out a study comparing the application of Hyland's (2000) move model in the abstracts of research articles on management written in English and Russian. The study revealed that most English written abstracts adopted Hyland's model, while those written in Russian used a move structure containing PMP or purpose, method and product only. The Russian research abstracts rarely included introduction and conclusion. In short, recent studies on RAs examined only the move model displayed in the abstracts or what Santos (1996, p.483) named as "features that constitute the abstracts of research articles at the macro level of textual organization" and research which looks into "the actual textual properties of RAs or the micro level of textual analysis" is still sparse.

Santos (1996) research abstract analytical framework is one of the most notable frameworks which can be used by a researcher to take a comprehensive look at how a research abstract is constructed. Despite a useful analytical framework, there are only a few studies which have used it as it appears in the original form. For example, Pho (2008) examine 30 research abstracts in the field of applied linguistics and educational technology and used Santos analytical framework. However, her study did not "divide the moves further into sub-moves" as appeared in the original model (p. 234).

Against this background, this study seeks to examine both the macro and micro level of textual organization of RAs accompanying the articles published in Indonesian journal of applied linguistics which is indexed in Scopus and regarded as one of the most highly respected scholarly journals in Indonesia. To be more specific, at the macro level, I analyzed the move structure of the RAs using Santo's (1996) five-move pattern and followed with more detailed analysis of each of the moves (inclusive of sub-moves) or known as micro level analysis.

\section{Literature Review}

In this section of the article, some other relevant previous studies are presented. Al-Ali and Sahawneh (2011) conducted a study aiming to analyze the rhetorical aspects of one hundred Ph.D. dissertation abstracts in which fifty of which were written in English by English speakers and the other fifty written in Arabic by people originating from Arab nations. The results revealed that both English and Arabic written abstracts used different generic structures and the difference was possibly caused by the socio-cultural and linguistic backgrounds. Can, Karabacak, and Qin (2016) carried out a research looking into the move structures of abstracts of articles written within the area of applied linguistics and analyzed them against the abstracts of past research. They found that around fifty percent of the abstracts excluded introduction and discussion components and concluded that authors tended to unfollow the move structures as stipulated in the journal. Darabad's (2016) research which studied the rhetorical structure of a total of 63 abstracts in three journals of different fields showed at least two interesting results. First, introduction was found to be "the least move and the most frequent move pattern was 
PMRC" and second, "the use of mix moves" had been seen as the major cause of difference among the three journals (p.136). To conclude, existing studies have shown some common and different results which can mean that research into the textual organization of abstracts is always a unique one and needs further and continuous investigation. This is particularly important in order to see whether there is a change of trend in the structure or organization of the research abstracts over time.

\section{Methodology}

\section{Research Questions}

The present study seeks to answer two major questions, namely:

- What type of move structure used most or least frequently in RAs published in Indonesian Journal of Applied Linguistics?

- What specific features of RAs employed by the authors of the abstracts published in the Indonesian Journal of Applied Linguistics?

\section{Corpus Construction}

A total of 25 research article abstracts were selected randomly from Indonesian Journal of Applied Linguistics (IJAL). This journal was chosen because it was the only applied linguistics journal from Indonesia indexed in Scopus (as of 2018) and one of the most highly respected applied linguistics journals in the Southeast Asian region. Since the five-move pattern proposed by Santo is only applicable to RAs, the abstracts of other types of articles (e.g. review articles) appeared in this journal were excluded in the corpus. The RAs in the corpus were published in 2016, 2017 and 2018.

\section{Data Analysis Procedures}

First, to answer research question number 1, all the 25 abstracts were skimmed to identify the type of move structure used. To be more specific, in this part of analysis, I analysed every sentence in each abstract and related it with IMRAD (Introduction, Method, Results and Discussion). During this process, I began to make notes whether the abstracts were written using this model or different one. To answer research question number 2, I adopted the RA analysis framework formulated by Santos (1996) which categorized features of abstract into a five-move pattern: situating the research (move 1), presenting the research (move 2), describing the methodology (move 3), summarizing the results (move 4), and discussing the research (move 5). Three moves (1, 2 and 5) were further broken down into 4, 3 and 2 sub-moves respectively (see table 1 for the details). Every sentence in the sample abstracts was analysed against each move or submove of this RA analysis framework.

\section{Table 1 Santo's (1996) five-move pattern}

\begin{tabular}{ll}
\hline Move 1 & $\begin{array}{l}\text { Situating the research } \\
\text { Sub-move 1A Stating current knowledge } \\
\text { and/or }\end{array}$ \\
& Sub-move 1B Citing previous research \\
& and/or \\
Sub-move 1C Extending previous research & Sub-move 2 Stating a problem \\
Move 2 & Presenting the research \\
& Sub-move 1A Indicating main features \\
\hline
\end{tabular}




\begin{tabular}{ll}
\hline & \multicolumn{2}{c}{ and/or } \\
& Sub-move 1B Indicating main purpose \\
and/or & Sub-move 2 Hypothesis raising \\
Move 3 & Describing the methodology \\
Move 4 & Summarizing the results \\
Move 5 & Discussing the research \\
& Sub-move 5A Drawing conclusions \\
& Sub-move 5B Giving recommendations
\end{tabular}

Source: Author

\section{Findings and Discussions}

\section{Move Structure Analysis}

The analysis of RAs' move structure (as shown in table 2) indicated that move 3 (describing the methodology) appeared in almost every abstract followed by move 2 (presenting the research) and move 4 (summarizing the results). There was only one abstract which did not incorporate move 2 and move 4 . Move 1 (situating the research) was the move that was least frequently used in RAs of this study. Like move 1 , move 5 (discussing the research) was also less popular as it was only used in 17 out of 25 RAs or $68 \%$.

\section{Table 2 Move Occurrence}

\begin{tabular}{lcc}
\multicolumn{1}{c}{ Moves } & Frequency & Percentage \\
\hline Situating the research & 13 & $52 \%$ \\
Presenting the research & 25 & $100 \%$ \\
Describing the methodology & 25 & $100 \%$ \\
Summarizing the results & 25 & $100 \%$ \\
Discussing the research & 17 & $68 \%$ \\
\hline
\end{tabular}

Source: Author

The analysis of the types of moves pattern (table 3) showed that authors preferred SPMRD moves pattern (10 abstracts) followed by PMRD (5 abstracts), PMR (abstracts) SPMR (3 abstracts) and PMSRD (2).

Table 3 Abstract Moves Pattern

\begin{tabular}{cc}
\hline Type & Number of abstract \\
\hline S-P-M-R-D & 10 \\
P-M-R-D & 5 \\
P-M-R & 5 \\
P-M-S-R-D & 2 \\
S-P-M-R & 3 \\
Total & 25 \\
\hline
\end{tabular}

Note: S: situating the research, P: presenting the research, M: describing the method, R: summarizing results, and D: discussing the research.

Source: Author 


\section{Specific Features of Research Abstracts: Move 1 is Situating the Research}

This is "an initial move which locates the current research in terms of research field and topic and is particularly included in an abstract to "attract a busy readership" (Santo, 1996, p. 486). Santo further points out that move 1 "provides orientation to the reader in relation to where the writer is coming from while motivating the reader to examine the research to be reported"'(p. 486).

Analysis of move 1 data used by 13 RAs revealed that majority of authors used either sub-move 1A (stating current knowledge) or sub-move 2 (stating the problem) or a combination of both as a way to situate their research. There was only one abstract which used sub-move 1B (citing previous research) to serve this purpose and none considered using sub-move $1 \mathrm{C}$ (extending previous research). Below are some examples of excerpts of sub-move $1 \mathrm{~A}, 1 \mathrm{~B}$ and 2 used in the sampled abstracts.

Sub-move 1A:

- "Students' learning engagement (SLE) has been the focus of educational research at least since the 1990s" (Suherdi, 2018, p.11).

- "Recently there has been a shift in humor studies, emphasizing linguistic humors and involving the field of rhetoric" (Rochmawati, 2017, p. 149).

- "Difficulties encountered by students in L2 academic writing has been a subject of research for several decades" (Bian \& Wang, 2016, p. 20).

Sub-move 1B:

- "Studies showed that interest in anime motivates students to learn the Japanese language and culture" (Chan, Wong, \& Ng, 2017, p.93).

Sub-move 2:

- "Myriads of theories account for the primacy of digital literacy on ELT as the demand of the $21^{\text {st }}$ century, yet studies on digital media literacy of distinct English teacher generations are thin on the ground" (Kurniawati, Maolida, \& Anjaniputra, 2018, p. 28).

- "Despite extensive studies on the role of segmental features and related issues in listening and speaking, there is paucity of research on the role of suprasegmental features in the same domain" (Mahmoodi \& Zekrati, 2016, p.28).

\section{Move 2: Presenting the research}

Move 2 is an essential part in any RA patterns as it "justifies the article either by describing the key features of the research in question or by presenting its purpose" (Santos, 1996, p. 488). All the RAs of this study contained move 2 indicating that it is an obligatory move for any abstract moves pattern or genre. This evidence corroborates the findings of Santo's study which also identifies the presence of move 2 in all RAs. It is also evident in the data that 12 abstracts were started with move 2 whilst in others' (13 abstracts), move 2 was written right after move 1. It could be learnt from this evidence, also the evidence of Santo's (1996) study, that the majority of RAs in any applied linguistics journals use move 2 as the opening sentence (s) of the abstracts or as the move written after move 1.

Move 2 can be written in three forms: a descriptive form to indicate main features (sub-move 1A), a purpose form to indicate the research purpose (sub-move 1B), and hypothesis testing (sub-move 2). It can be inferred from the data that authors seemed to employ "a clearly predominating formula-like pattern in the corpus to signal their Move 2" (Santos, 1996, p. 489). For example, as can be seen in Table 4, in writing the sub- 
move 1A sentence (s), authors started with 'this' (24) and 'the'(1) or as Santos named them as deictic items and followed by the mention of the manuscript genre such as article (2), research (4), study (14), and paper (5). As for this study, this formula-like pattern applies only for deictic item and report genre and is not applicable to the reporting verb since it has a variety of reporting verbs. In the previous research (e.g. Santos, 1996), there were only 5 reporting verbs used in 46 RAs. In other words, some reporting verbs (e.g. focus, delineate, explicate) which were not common in previous research are now used in this study's RAs. Some instances are shown in the excerpts below:

- "This study focuses on describing a bilingual infant's comprehension of adults' verbal input..." (Adnyani, Beratha, \& Suparwa, 2017, p.11).

- "This article delineates a case study investigating the development of levels of reflection encapsulated in reflective teaching practice..." (Nurfaidah, Lengkanawati, Sukyadi, 2017, p.82)

- "This paper will explicate how this framework of analysis works as well as describing the nature of SLE in an English as a foreign language (EFL) teaching" (Suherdi, 2018, p.11)

Table 4 Move 2/Sub-move 1A

\begin{tabular}{lll}
\hline Deictic item & Genre & Reporting verb \\
\hline This (24) & Article (2) & Investigates (1) \\
The (1) & Research (4) & Investigated (2) \\
& Study (14) & Explores (2) \\
& Paper (5) & Explored (1) \\
& Examines (2) \\
& Reports (2) \\
& Explicate (1) \\
& Focuses (2) \\
& Exposed (1) \\
& Delineates (1) \\
& Try (1) \\
\hline
\end{tabular}

Source: Author

For the sub-move 1B, it can be inferred from the corpus that majority of RAs ( 8 out of 11) used the verb phrase 'this study aims(7)/aimed to (1)...'while the rest applied 'the purpose of this study is to (2)...' and 'the study was conducted to'...(1). As in the case of sub-move $1 \mathrm{~A}$, the evidence identified in sub-move $1 \mathrm{~B}$ also showcases a rather different fact where the first and third verb phrases for expressing purposive statement were not present in the work of Santos (1996) in spite of the fact that he collected more RAs with the purposive sub-moves (26).

With regard to the sub-move 2 (hypothesis), there was only one author who used this style for presenting the research in the abstract in exchange of other two sub-moves (indicating main features and purpose)(see the excerpt below as an example). In Santo's (1996) research, this sub-move was used mostly as the supporting point only or used after the sentence (s) indicating sub-move $1 \mathrm{~A}$ and $1 \mathrm{~B}$, whereas in this present study, it played a major role as a way to present the research.

- "This study investigates whether indirect corrective feedback is effective on students' writing accuracy and whether there is any interaction between corrective feedback and students' levels of grammatical sensitivity" (Septiana, Sulistyo, \& Kadarisman, 2016, p.1). 


\section{Move 3: Describing the methodology}

This move points to the procedure of a research and the information is considered adequate when it contains the description about the study participants/materials, data collection instrument(s) and analysis strategy. Analysis of the move 3 data reveals that there are four different types of move 3 pattern in the sampled RAs: 1.) move 3 independent to other move(s) or occurs by itself and with adequate information, 2). move 3 independent to other move(s) but with less adequate information, 3). Move 3 embedded with other move(s) and with adequate information, and 4). Move 3 embedded with other move(s) but with less adequate information. There are 9 RAs with move 3 type 1 and 10 RAs with type 2 . Most of type 2 research abstracts are inadequate due to the absence of analysis strategy and this might occur for the reasons including abstract word limit as required by the Indonesian Journal of Applied Linguistics and author's belief that details of the methodology could be viewed later in the paper by readers. The following are the examples of move 3 of type 1 and type 2 as written by the authors:

- Type 1: "a quasi-factorial design was adopted for this research. The subjects of the study were fourth-semester students of English Department, at a State University in Malang, selected randomly. The experimental group was treated with indirect corrective feedback and the control group with direct corrective feedback. A parametric statistical test, ANCOVA, was used to test the hypotheses" (Septiana, Sulistyo, \& Kadarisman, 2016, p.1)

- Type 2: "to achieve this aim, a qualitative case study design involving analysis of English teachers' report texts and interviews with these English teachers was employed in this research" (Sudarsono, Yunitasari, \& Gunawan, 2016, p.141).

While type 1 and 2 of move 2 are independent to other moves, type 3 and 4 are written as part of other moves. There 2 RAs whose move 3 belongs to type 3 category. One move is embedded with move 2 (presenting the research) and the other is with move 4 (results). One instance is presented below.

- 'Using descriptive statistics and ANCOVA to analyse the students' scores on the pre- and the post-tests, the results showed that ..." (Bataineh \& Obeiah, 2016, p.12).

Parts of move 3 (setting, participants and data collection) of the RA are written independently but the analysis approach is embedded with move 4. Instead of specifically describing the data analysis strategy exclusively or as part of move 3 , the author prefers to mix with it the study results which follow the methodology part. Further, there is only one instance of type 4 of move 3 identified in the data and it is embedded with move 2 .

- "This article delineates a case study investigating the development of levels of reflection encapsulated in reflective teaching practice of four Indonesian EFL preservice teachers during their field teaching" (Nurfaidah, Lengkanawati, \& Sukyadi, 2017, p.82)

\section{Move 4: Summarizing the results}

Move 4 provides information about how the author summarizes their research findings and they have to be fairly and objectively reported (Marwan, 2017; Kallestinova, 2011; Santo, 1996) According to Santos (1996), some lexical items or nouns that are commonly used as the opening signal of this move include, among others, "results, analysis, study, findings, outcome, evidence, data, and research" (p.493). In the corpus of this research, there are only four opening signals used namely findings, results, study, 
and analysis. Findings and results are used more frequently (10 and 8 RAs respectively) than the two others (study: 3 and analysis: 2). The absence of other opening signals like outcome, evidence, data, and research might be due to the reason of commonality in the sense that past authors of applied linguistics RAs were used to opening their move 2 with findings and results and this trend is then replicated by the current and future authors. Then, from a total of 25 RAs sampled, two abstracts seem to use a rather different way of signaling the opening of move 4 . In spite of opening move 4 with any of the above lexical items, the author prefers to use a conclusion-like sentence to indicate research findings. For example, one of the author writes, "in general, more students associated in-class lessons with higher motivation and more interest, due to better understanding, valued classroom interaction with the lecturer and peers, and input from the lecturer" (Wright, 2017, p.64). In the previous move of this abstract (move 3), the author used a Likert-scale questionnaire. In many other applied linguistics RAs, if this type of instruments is in use, authors usually signal move 3 with one of the opening lexical items (results, findings, etc) (see Santo, 1996 for review). In short, the current example of move 4 opening is an exceptional case and was not evident in the previous research.

Following the opening signal to indicate the part of move 4 in the abstract is the use of verbs. Analysis of the corpus shows that past verbs are used by 11 RAs and the other 14 used the present verbs. It is also evident in the move 2 data that 7 different verbs are used by authors to start informing their research findings. The word 'show' is used by more than half of RAs or 14 and followed with verbs 'indicate' (4), reveal (3) and demonstrate (1), find (1), discover (1) and value (1). This fact suggests that verb 'show' is more popularly used in this journal RAs. Example of how each of these verbs is shown below.

- The results show ... (present tense)

- The results indicate ... (present tense)

- The findings revealed ...(past tense)

- The findings demonstrate (present tense)

- More students ...valued ... (past tense)

- The findings discovered ....(past tense)

- The study found ...(past tense)

\section{Move 5: Discussing the research}

"The purpose of the discussion section is to explain what your results mean and what contribution your paper makes to the field of study" (Annesley, 2010, p.1671). This move can be further classified into two sub-moves: drawing conclusions and giving recommendations. According to Santos (1996, p.495), conclusion statements "offer explanations for the results summarized in move 4" and they "can occur either embedded inside move 4" or in a differently constructed sentence. Similar to the findings in Santo's study, sub-move 1 in this study also uses a number of signals to indicate conclusions. The verb suggest is one of the most popular verbs used in the corpus to signal conclusions and the examples are provided below.

- The study suggests a call to ...

- The findings suggest that the lecturer ...

Verb phrase it is/was concluded, as shown in the below example, is also common to signal the conclusion statement. 
- It was concluded that the provisions of ...

Also, linking phrases like based on the results/findings are identified in the current corpus. An example is given below.

- Based on the results, discussions on possible contributing factors ...

Interestingly, the use of deictic references like this and these is not identified in this research. This phenomenon is in in stark contrast with the findings of previous research (Santos, 1996) which recorded the frequent use of deictic references.

Next, sub-move 2 (recommendations) "outlines suggestions for future practice or investigation" (Santos, 1996, p. 496). In the current study, this sub-move type which indicates recommendations can be identified in 4 RAs. The examples are given below.

- "Based on the possible limitations of the study, furthermore, some directions for future studies are also presented" (Subekti, 2018, p.57)

- Further research to investigate other elements ...

- ...how to strengthen future research in this area of inquiry ...

- ...there are many areas for further studies in the teaching ...

The remaining abstracts contain sub-move 2 which suggests for future practice such as the one shown in the following example.

- "This paper argues that reform in language teacher education needs to address factors that hinder preservice teachers from implementing instructions which aligns with the theoretical beliefs espoused by their teacher training program" (Othman \& Kiely, 2016.p.50)

\section{Conclusion}

The analysis of moves pattern or macro-organization of RAs from the Indonesian Journal of Applied Linguistics (IJAL) has shown that the SPMRD is the most common moves pattern used in the abstracts. This fact shows that the authors prefer to organize their RAs using the sequence of situating the research $(\mathrm{S})$, presenting the research $(\mathrm{P})$, describing the method (M), summarizing results (R), and discussing the research (D). It can be inferred from the analysis that the presenting the research move, describing the method move, and summarizing the results move are obligatory as they appear in all the RAs. Both the discussing the research move and the discussing the research move are fairly common in the abstracts of IJAL.

First, the analysis of move 1 (situating the research) indicates that stating the current knowledge (sub-move 1A) and stating the problem (sub-move 2) are the most frequent sub-moves in the abstracts. Whereas citing previous research (sub-move $1 B$ ) becomes the least frequent move. Surprisingly, there is no single abstract which uses extending previous research or the sub-move $1 C$. The absence of sub-move $1 \mathrm{C}$ is possibly due to the lack of interest from the IJAL authors to extend other people's research. Secondly, the analysis of the presenting the research (move 2 ) has shown that majority of the RAs use this move as the opening sentence (s) of the abstracts or as the move written right after move 1 . Thirdly, move 3 analysis reveals that majority of the RAs (19) employed type 1 (independent to other move(s) or occurs by itself and with adequate information) and type 2 (independent to other move (s) but with less adequate information) of move 3 . Fourthly, analysis of move 4 (summarizing the results) shows that the nouns like findings and results are the most frequent nouns used in this move 
followed by study and analysis. Lastly, the verb suggest is used most frequently to signal move 5 or discussing the research in the RAs.

Finally, despite some interesting findings, this research is not without methodological limitations. First, only one Indonesia's Scopus-indexed journal was considered, which, to some extent, may limit the understanding of the phenomena under investigation. It is, hence, recommended that future study analyse RAs from several Scopus-indexed journals either from the same discipline (i.e. applied linguistics) or different disciplines.

Second, the current research included only 25 RAs from the IJAL journal, thus limiting the full understanding of the case. Future research should consider incorporating more than half of, if not all, the RAs published in this journal. Finally, in order to understand authors' selection of moves pattern and ways in writing each move of the research abstract, further investigations can consider undertaking interactions with the authors, for example, through focus groups or individual interviews.

\section{Reference}

Al-Ali, M. N. \& Sahawneh. Y. B. (2011). Rhetorical textual organization of English and Arabic Ph.D. dissertation abstracts in Linguistics. SKY Journal of Linguistics, 24(2011), 7-39.

Andrade, C. (2011). How to write a good abstract for a scientific paper or conference presentation. Indian Journal of Psychiatry, 53(2), 172-175.

Adnyani, N. L. P. S., Beratha, N. L. S., \& Suparwa, I. N. (2017). Child comprehension of adults' verbal input: A case of bilingual acquisition in infancy. Indonesian Journal of Applied Linguistics, 7(1), 11-18.

Annesley, T. M., (2010). The discussion section: Your closing argument. Clinical Chemistry, 56(11), 1671-1674

Bataineh, R. H. \& Obeiah, S. F. (2016). The effect of scaffolding and portfolio assessment of Jordanian EFL writing. Indonesian Journal of Applied Linguistics, 6(1), 12-19.

Belt, P., Mottonen, M., \& Harkonen, J. (2011). Tips for writing scientific journal articles. Oulu: University of Oulu.

Bian, X. \& Wang, X. (2016). Chinese EFL undergraduates' academic writing: Rhetorical difficulties and suggestions. Indonesian Journal of Applied Linguistics, 6(1), 20-29.

Can, S., Karabacak, E., \& Qin, J. (2016). Structure of moves in research article abstracts in applied linguistics. Publications, 4(23), 1-16.

Chan, Y. H., Wong, N. L., \& Ng, L. N. (2017). Japanese language students' perceptions of using anime as a teaching tool. Indonesian Journal of Applied Linguistics, 7(1), 93-104

Darabad, A. M. (2016). Move analysis of research article abstracts: a crossdisciplinary study. International Journal of Linguistics, 6(2), 125-140.

Hyland, K. (2000). Disciplinary discourses: Social interactions in academic writing. Harlow, UK: Pearson Education.

Kallestinova, E. D. (2011). How to write your first research paper. Yale Journal of Biology and Medicine, 84(3), 181-190. 
Kurniawati, N., Maolida, E. H., \& Anjaniputra, A. G. (2018), The praxis of digital literacy in the EFL classroom: Digital-immigrant vs digital-native teacher, Indonesian Journal of Applied Linguistics, 8(1), 28 - 37.

Mahmoodi, M. H. \& Zekrati, S. (2016). Relationship among brain hemispheric dominance, attitude towards L1 and L2, gender, and learning suprasegmental features. Indonesian Journal of Applied Linguistics, 6(1), 112 - 124.

Marwan, A. (2017). The assessment of English teachers' ability to write a scientific article in English. Lingua Cultura, 11(2), 109-114.

Morton, C. (2007). Submission to Print: Submitting a Paper for Publication and the Publishing Process. In Soule, D. P.J., Whiteley, L., \& McIntosh, S. (Eds), Writing for Scholarly Journals Publishing in the Arts, Humanities, and Social Sciences (32- 42). Glasgow: eSharp.

Noorizadeh-Honami \& Chalak. (2018). Comparative analysis of architecture research article abstracts written by native and non-native authors: a cross-linguistic, cross-cultural study. Theory and Practice in Language Studies, 8(3), 325-330.

Nurfaidah, S., Lengkanawati, N. S., \& Sukyadi, D. (2017). Levels of reflection in EFL pre-service teachers' teaching journal. Indonesian Journal of Applied Linguistics, 7(1), 80-92.

Othman, J. \& Kiely, R. (2016). Preservice teachers' beliefs and practices in teaching English to young learners. Indonesian Journal of Applied Linguistics, 6(1), 5059.

Pho, P. D. (2008). Research article abstracts in applied linguistics and educational technology: a study of linguistic realizations of rhetorical structure and authorial stance. Discourse Studies, 10(2), 231-250.

Rochmawati, D. (2017). Pragmatic and rhetorical strategies in the English-written jokes. Indonesian Journal of Applied Linguistics, 7(1), 149-159.

Santos, M. B. D. (1996). The textual organization of research paper abstracts in applied linguistics. Text, 16(4), 481-99.

Septiana, A. R., Sulistyo, G. H., \& Kadarisman, A. F. (2016). Corrective feedback and writing accuracy of students across different levels of grammatical sensitivity. Indonesian. Journal of Applied Linguistics, 6(1), 1-11.

Subekti, A. S. (2018). L2 motivational self-system and L2 achievement: A study of Indonesian EAP learners. Indonesian Journal of Applied Linguistics, 8(1), 5767.

Sudarsono, M. I. S., Yunitasari, D., \& Gunawan, M. H. (2016). Investigating teachers' professional competence: A systemic functional linguistic analysis of teachers' report texts. Indonesian Journal of Applied Linguistics, 7(1), 141-148.

Suherdi, D. (2018). SMSLEFA: An alternative synergistic multilayered analysis of students' learning engagement in EFL context. Indonesian Journal of Applied Linguistics, 8(1), 11-20.

Wright, B. M. (2017). Blended learning: Student perception of face to face and online EFL lessons. Indonesian Journal of Applied Linguistics, 7(1), 64-71.

Zanina, E. (2017). Move structure of research article abstracts on management: Contrastive study (the case of English and Russian). Journal of Language and Education, 3(2), $63-72$. 